\title{
SUPRAVALVAR PULMONARY AND AORTIC STENOSES COEXISTING
}

\author{
BY \\ GEOFFREY H. WATSON \\ From the Department of Child Health, the University of Manchester, and the Royal Manchester Children's Hospital \\ Although patients with pulmonary stenosis or aortic stenosis are often seen it is unusual for a \\ patient, to have both defects. I have found reports of only 14 such cases but, as the first was pub- \\ lished only nine years ago, the anomaly may be less rare than the numbers suggest. Various \\ combinations of obstructive lesions have been present and, as several cases have presented consider- \\ able surgical difficulty, full pre-operative diagnosis is important. The present case illustrates the \\ value of selective angiocardiography in the investigation of atypical ventricular outflow obstructions.
}

\section{Case Report}

A girl aged 20 months was thought by her parents to be slightly short of breath on exertion but was otherwise in good health. There was no relevant personal or family history.

She was of small build, weighing only $21 \mathrm{lb}$. $(9.5 \mathrm{~kg}$.), but the only significant abnormalities on physical examination were in the cardiovascular system. The cardiac impulse suggested some right ventricular enlargement, though the apex beat was palpable. A grade 4/6 systolic murmur of ejection type was maximal in the left second and third intercostal spaces, where it was accompanied by a thrill, but was also quite loud in the right first intercostal space. No ejection sound or diastolic murmur was heard, but the second sound was clearly split in the left third and fourth intercostal spaces, the degree of splitting varying a little with respiration. Phonocardiograms in the aortic and pulmonary areas (Fig. 1) showed murmurs of similar pattern. An electrocardiogram showed evidence of right ventricular enlargement, but RV1 was only $7 \mathrm{~mm}$., and there was a prominent $S$ in V2. A chest radiograph showed a normal heart outline with normal lung vascularity, though the thymus obscured details of the upper mediastinum.

By cardiac catheterization it was possible to exclude any sizeable shunts, but severe pulmonary stenosis was demonstrated at about the level of the valve, the pressures recorded being $7 / 2$ in the right atrium, 95/3 in the right ventricle, and $22 / 9 \mathrm{~mm}$. $\mathrm{Hg}$ in the pulmonary trunk. Right ventricular selective cine-angiocardiograms (Fig. 2) showed a severe supravalvar pulmonary stenosis at the level of the distal limits of the sinuses of Valsalva, the narrow zone having a diameter of about $3 \mathrm{~mm}$. The right ventricular outflow tract was wide in diastole, but became narrowed to about $2 \mathrm{or} 3 \mathrm{~mm}$. at the end of systole. The pulmonary valve ring was smaller than usual, but the valve cusps moved well and did not appear to be thickened: during systole they lay against the walls of the sinuses of Valsalva and did not seem to cause obstruction additional to that offered by the supravalvar stenosis. There was striking post-stenotic dilatation of the pulmonary artery, but the peripheral pulmonary vasculature and left heart appeared normal, though the aortic root was abnormal.

The left heart was entered with some difficulty through a foramen ovale: the pressures recorded were $12 / 5$ in the left atrium and $135 / 5 \mathrm{~mm}$. $\mathrm{Hg}$ in the left ventricle, where the tracings showed rounded systolic peaks. The blood pressure taken in each arm by sphygmomanometer immediately afterwards was $90 / 70 \mathrm{~mm}$. $\mathrm{Hg}$. A left ventricular cine-angiocardiogram (Fig. 2) showed a supravalvar aortic stenosis rather similar to the pulmonary stenosis, though less severe; the aortic cusps could not be made out, but did not appear to add to the obstruction caused by the supravalvar ring. There was a mild post-stenotic dilatation of the ascending aorta, but the rest of the aorta and its branches, including the coronary arteries, were normal. 


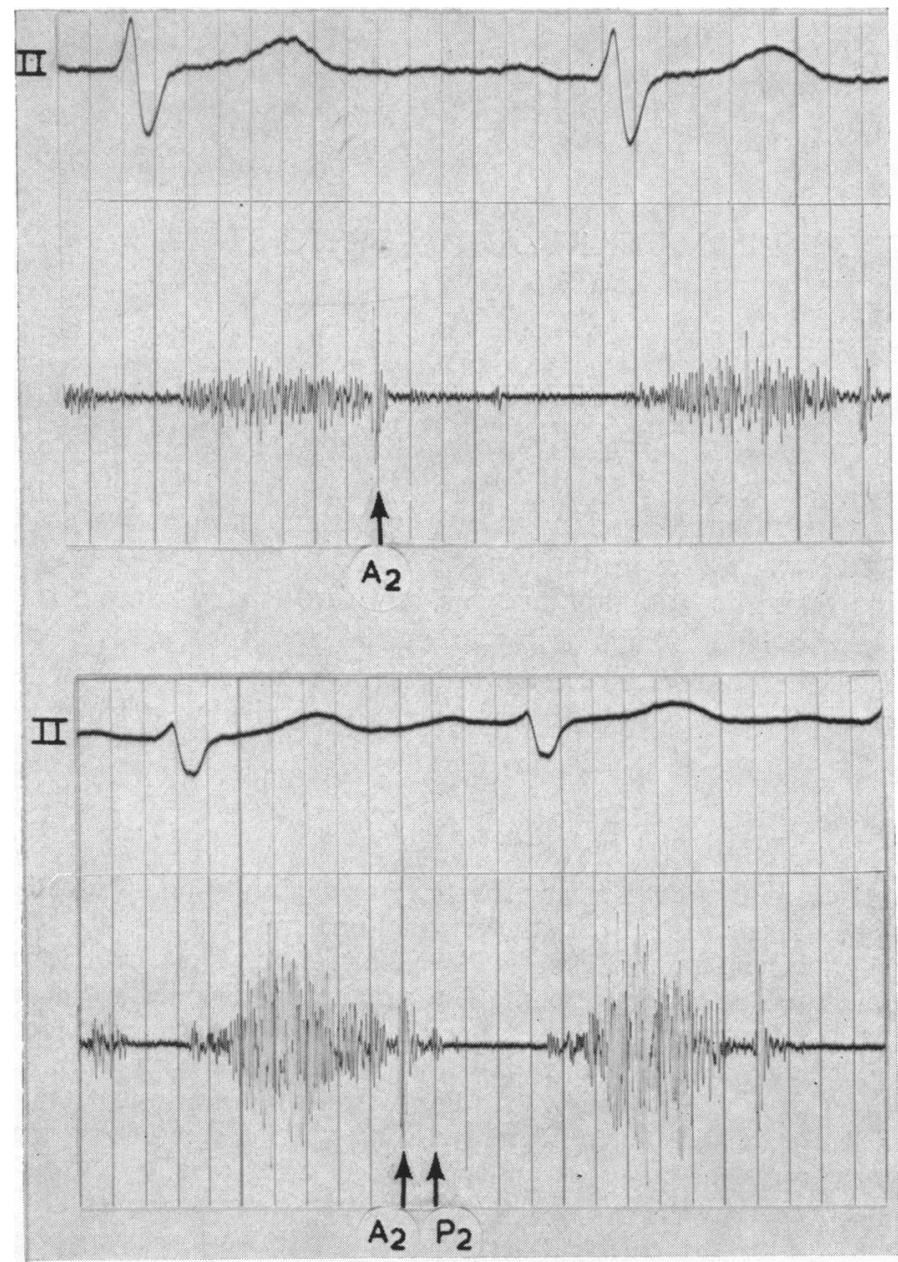

FIG. 1.-Phonocardiograms-H.F. Above: right first intercostal space. Below: left second intercostal space.

\section{Discussion}

Reports have been published showing that of 14 patients who had both pulmonary and aortic stenosis(Nadas et al., 1962, four cases and earlier references; Richter, 1953; Edwards and Jones, 1962; and Ellis, Ongley, and Kirklin, 1962), 2 had corrected transposition of the great vessels. Of the 12 with no ventricular inversion 2 had subvalvar pulmonary and aortic stenosis; 5 had pulmonary and aortic valvar stenoses with or without infundibular stenosis; 1 had valvar pulmonary and supravalvar aortic stenoses; 3 had pulmonary valvar stenosis with small valve rings and obstruction below, at, and above the aortic valve respectively; and the first case recorded-that of Richter (1953)-had small pulmonary and aortic valve rings, with supravalvar stenoses at the level of the commissures. One patient was a mongol and two others were mentally retarded, one having several other minor congenital defects, the other an atrial septal defect. Two other children had small septal defects, one atrial, the other ventricular; and a third had a patent ductus and syndactyly. Clearly there is a high incidence of the less common types of obstruction and of associated defects.

The unfavourable anatomical configuration has been largely responsible for the high mortality, 


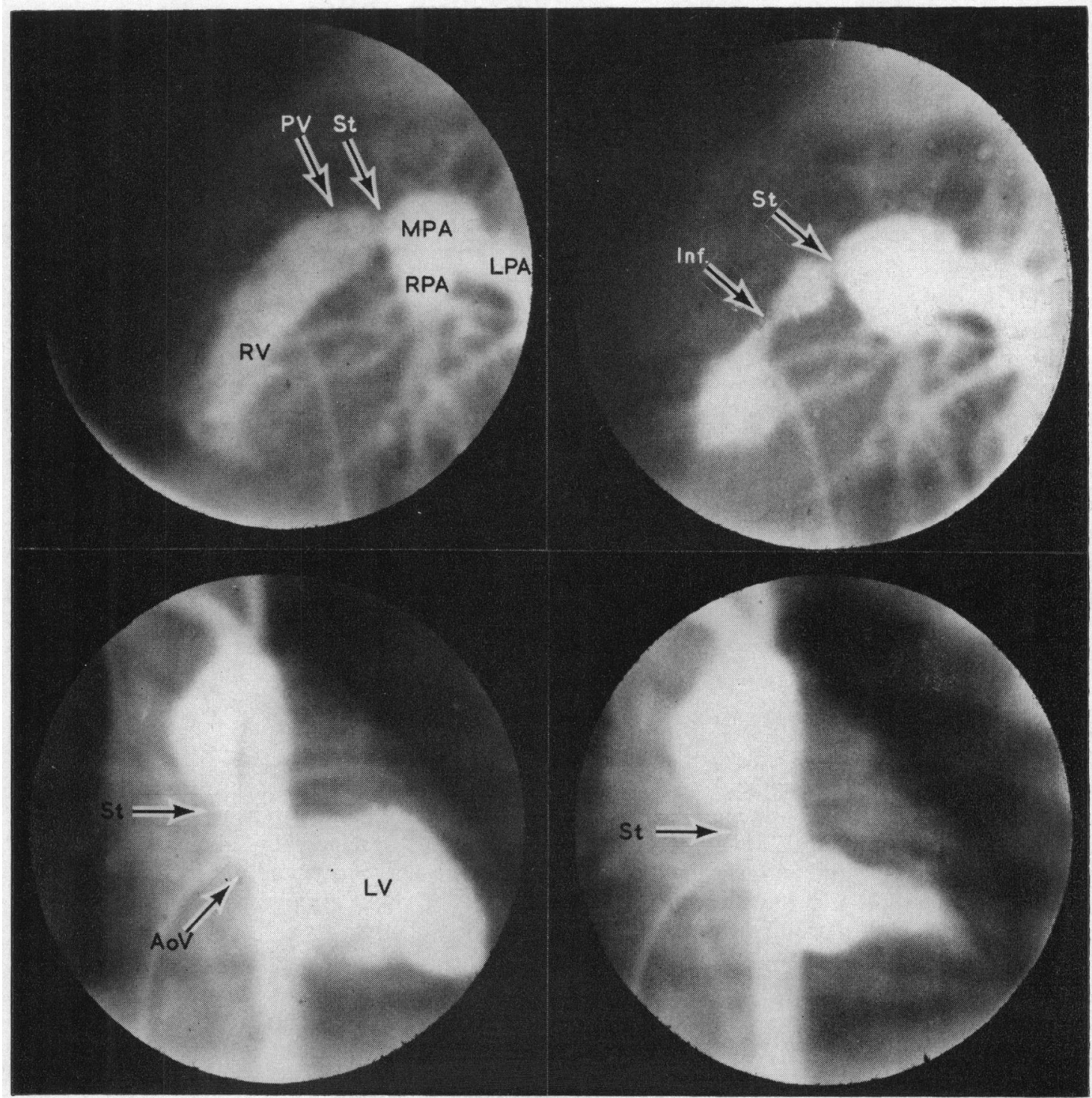

Fig. 2.-Selective cine-angiocardiograms. Above: right ventricle, left lateral views. Below: left ventricle, posteroanterior views. On left: late diastole. On right: late systole.

AoV: Aortic valve cusps.

PV: Pulmonary valve cusps.

$\mathrm{St}$ : Supravalvar stenosis.
Inf.: Systolic infundibular narrowing.

MPA: Main pulmonary artery.

RPA: Right pulmonary artery.

LPA: Left pulmonary artery.

for operation has been successfully performed in only three of the reported cases, in two of whom the obstructions were all short and subvalvar. The relief of only one of the stenoses is likely to be fatal, and as Sissman et al. (1959) points out accurate diagnosis is vital if this mistake is to be avoided.

The physical findings, when mentioned, usually suggested pulmonary stenosis, but there were nearly always atypical features; particularly the unexpected loudness of the murmur in the right 
first intercostal space, a cardiac impulse suggesting enlargement of both ventricles, and in two cases an apical mid-diastolic murmur, presumably due to hypertrophy of the ventricular septum (Nadas et al., 1962) though these were the two with corrected transposition. Only one case had signs of aortic stenosis alone. In several, however, the only unusual finding on physical examination was the widespread diminution in intensity of the second sound. The degree of splitting of the second sound should depend upon the relative severity of the outflow stenoses, but only Edwards and Jones (1962) discuss this point. Some of these features might well be difficult to elicit in small children. In Case 1 of Nadas et al. the systolic murmur in the aortic area was loudest early in systole, as it is in aortic stenosis, whereas in the pulmonary area the maximal point was later in systole as in pulmonary stenosis, but in the present case no such differentiation was possible.

Chest radiographs sometimes showed evidence of unexpected ventricular enlargement. The cardiogram in one case showed only the changes of left ventricular enlargement, but in all the others there was evidence of right ventricular enlargement. Although there was often little direct evidence of left ventricular enlargement, there were usually some unusual features such as a low voltage RV1, an inverted T in V6 or, especially, a deep S in V1 or V2.

In none of the reported cases were the combined findings on physical examination, electrocardiography, and radiography quite typical of aortic or pulmonary stenosis. It is reasonable to conclude that although atypical features in cases of apparent pulmonary or aortic stenosis, particularly those indicating involvement of both ventricles, may be due to various additional defects, the presence of such features should always suggest the possibility of obstruction to both ventricular outflow tracts. If pressure recordings should confirm the suspicion then angiocardiography, by multiple injections if necessary, seems advisable in view of the frequency of unusual stenoses with a high operative risk.

\section{Conclusion}

A case is presented of supravalvar obstruction at the aortic and pulmonary valves in a girl of 20 months. The presence of obstruction of both ventricular ostia should be suspected where signs of pulmonary or aortic stenosis are accompanied by unusual features and should be considered where there are other congenital anomalies. Patients with double stenoses should undergo full investigation of both the right and the left heart, particularly selective angiocardiography, as the anatomical arrangement is much more likely to be surgically unfavourable than in cases of isolated stenosis.

I am grateful to Dr. G. M. Komrower for allowing me to report this case and Professor W. F. Gaisford for helpful criticism.

\section{References}

Edwards, F. R., and Jones, R. S. (1962). Congenital aortic stenosis. Thorax, 17, 218.

Ellis, F. H., Ongley, P. A., and Kirklin, J. W. (1962). Results of surgical treatment for congenital aortic stenosis. Circulation, 25, 29.

Nadas, A. S., Van der Hauwaert, L., Hauck, A. J., and Gross, R. E. (1962). Combined aortic and pulmonic stenosis. Circulation, 25, 346.

Richter, G. W. (1953). Coexisting congenital stenoses of aortic and pulmonic ostia. Arch. Path., 56, 392.

Sissman, N. J., Neill, C. A., Spencer, F. C., and Taussig, H. B. (1959). Congenital aortic stenosis. Circulation, 19, 458. 